\title{
THE ESSENCE OF QUESTIONING AND EXPLICIT READING INSTRUCTION STRATEGY
}

\author{
SA’ DULLOH MUZAMMIL \\ Penulis adalah Pengajar di IAIN Pontianak
}

\begin{abstract}
Teacher's questioning may function to assist students comprehend more reading materials and to enable them to be proficient readers. Yet, the students may be less benefited from which if the teacher neither provides sufficient explicit reading strategy nor involves higher-level questions. Consequently, the teacher should pay more careful attentions as follows: 1) teacher should involve both lower- and high-lever questions; 2) teacher should provide students with explicit reading strategy; 3 ) teacher should be aware of the activities in reading phases: pre-, during-, and post-reading.
\end{abstract}

Key words: lower- and higher-level question, explicit reading strategy, and reading phases

\section{INTRODUCTION}

Reading activity in a classroom involves at least three components: students, teacher, and text. Students are readers who read and try to comprehend the text. Teacher is facilitator, guide, organizer, and evaluator. And text that is to be comprehended.

Reading comprehension activity in the classroom should be aimed at enabling students to be proficient readers. Snow (2002: xiii) identifies literacy proficiency is reached when a reader can read a variety of materials with ease and interest, can read for varying purposes, and can read with comprehension even when the material is neither easy to understand not intrinsically interesting....proficient readers...are capable of acquiring new knowledge and understanding new concepts, are capable of applying contextual information appropriately, and are capable of being engaged in the reading process and reflection on what is being read.
In other word, students should read materials easily and interestingly with good comprehension even though the materials they read are difficult and uninteresting, absorb new knowledge and understand new concept. As the result, they must also be able to reflect what is being read by evaluating, giving opinions, and proposing solutions.

To ensure whether or not students comprehend what they read. Teacher may propose questions. However, it is a misconception, in a classroom reading activity, when teacher distributes texts to students, asks them to read and he/she then questions them without providing strategies to answer the questions. It seems the teacher tests the students instead of teaching them to read. Even worse, he/she over use lower level questions rather than higher level question. It may take place since the teacher does not know how what to do and how to teach read. 
Consistent with the findings of the National Reading Panel and the RAND Reading Study Group, this panel states that effective adolescent literacy interventions must provide direct, explicit comprehension instruction in which various approaches are used. Specifically the Study Group identified the following instructional factors:

1. Comprehension strategies instruction, which is instruction that explicitly gives students strategies that aid them in comprehending a variety of texts;

2. Comprehension monitoring and metacognition instruction, which is instruction that teaches students to become aware of how they understand while they read;

3. Teacher modeling, which involves the teacher reading texts aloud, making her own use of strategies and practices apparent to her students;

4. Scaffolded instruction, which involves teachers giving high support for students practicing new skills and then slowly decreasing that support to increase student ownership and self-sufficiency; and

5. Apprenticeship models, which involve teachers engaging students in a contentcentered learning relationship (2002: 1314).

Explicit strategy instruction, moreover, may be employed since students need to be taught strategies in a very direct, visible way because explicit instruction provides a clear explanation of the tasks involved in comprehending. It also helps students to pay careful attention to each of the tasks and encourages them to activate their prior knowledge. Explicit teaching also invites the reader to breaks the task into small pieces, and it provides direct, continual feedback from the teacher, (flood, et al. 2006: 6).

The purpose of explicit strategy instruction is to facilitate independent learning. In order to become active, self- directed readers, students must have knowledge of themselves as readers, be cognizant of the strategies they use when deciphering texts, and select appropriate reading strategies and monitor the effectiveness of those strategies (Irvin, 1998 in flood, et al. 2006: 6).

Besides facilitating student with explicit strategy instruction, teacher should enhance students' reading performance standard. One of the efforts is by focusing not only on low level instruction but also highquality of level instruction of reading comprehension, in order that students can achieve proficiency of reading. Hence this article proposes an explanation and an alternative to teach reading and frame and organize questions in pre-, while-, and postreading.

\section{DISCUSSION}

\section{a. THE NOTION OF QUESTION}

According to Elliot, et al. (1996: 286) questioning was one of teaching most common and most effective teaching techniques. Using questioning is a specific example of how teachers can help students to improve their thinking skill. In line with preceded statement, Costa (1985: 126) in Elliot, et al. (1996: 290) stated that students derive their cues for expected behavior almost totally from teacher questions and statements. If we assume a relationship between the level of thinking in a teacher's statements and questions and the level of student thinking, then questions containing higher-order thinking will require students to use higher-order skills to answer them.

Furthermore, according to Cole and Chan (1994: 170) questioning is an interactive process which aims to engage students in the learning process and draw forth thoughtful responses. Questions promote learning and act in both direct and indirect ways to improve students' understanding of subject matter being taught. In addition, 'question asked by teachers can be used to comprehension of 
higher-level text as well' (Aebersold \& Field, 1997: 117).

Then, related to reading comprehension, Question-answering instruction can help students get more from their reading by showing them how to find and use information from a text to answer teacher's questions (Levin \& Pressley, 1981 in Lehr \& Osborn, 2005: 19). Learning question-answering strategies can also help students locate information in a text that is related to the question. (Lehr \& Osborn, 2005: 20).

Cole and Chan (1994: 173) classify questions into six categories, they are highand low-order questions, product, process and opinion questions, open and closed questions, what, when, how, who and why questions, memory questions and search questions, and contextually explicit, contextually implicit and background questions. Those are explained as follows:

First, high- and low-order questions, high-order questions are concerned with comprehension, application, analysis, synthesis or evaluation of subject matter. They are several types of high-order questions. Comprehension questions seek to determine students' understanding of content. Such question request students to explain summaries and elaborate on facts presented to them. Application questions ask students to go beyond the mere surface of knowledge in new situations. Analysis questions ask the students to separate content into parts and student to bring together disparate elements into a coherent whole. Finally, evaluation questions ask the students to make judgments and decisions about the worth of something, using defensible criteria in making of these judgments. While low-order questions request knowledge of subject matter of the recall of facts and specifics. These are also called fact question. Low order questions often lead to effective learning because teachers use these questions to review subject matter rather than to introduce new ideas.

Next, Good and Grous (1977) in Cole and Chan (1994: 1976) distinguish among product, process and opinion questions. Product questions require answers that are conclusions, end results or outcomes and usually prompt relatively brief answers. For example, a teacher may ask, "What were the three major causes of the Indonesian Reformation?" Process questions require students to explain the procedures, means to ends, or steps they have employed to find solutions or reach conclusions and usually call for extended student explanations rather than short answers. While open questions require that students make judgments, evaluate content, give viewpoints or state preferences. For example, a teacher may ask, "What is your opinion of the behavior or the previous regime before the Indonesian Reformation?" Such a question clearly requires value judgments as well as objective evidence to support these judgments. These questions are usually contrasted with other question types that require objective responses.

Third is open and closed questions. In this case, closed questions encourage convergent thinking and allow only a narrow range of prescribed responses. For example, a teacher may ask, "How did this story end?" these kind of questions demand specific and unambiguous responses. Open questions stress divergent or creative thinking and allow a wide range of acceptable responses. For example, "Can you think of another ending to this story?" These kinds of questions do not have "right" and "wrong" answers in the way that closed questions do. Answers to open questions are more appropriate, depending on the context.

Then come what, when, how, who and why questions. What questions usually involve knowledge or recall of key ideas and details. When questions require students 
to think about the temporal sequence of events (e.g. "What happened first in narrative?"). How questions are concerned with procedures and process (e.g. "What has to be prepared and done to make an omelet?"). Who questions require students to identify persons involved in particular narrative?'). Why questions require students to explain reasons for particular phenomena. The last category is often the most challenging of all because students have to understand causal relationships before they can answer these questions correctly.

The fifth category is memory questions and search questions. Here, memory questions require the recall of specifics of subject matter. Memory is a critical factor in school learning and the use of questions of this type will often improve students' capacity to organize their own learning. While search questions require that students discover the answers to questions. Students cannot rely on memory when seeking answers to these questions. In preparing answers to search questions, students have to refer to external sources, such as books and reference materials.

The last is contextually explicit, contextually implicit and background questions. Contextually explicit or literal questions require answers that are derived from the explicit content of the lesson or from the surface meanings in materials provided to the learner. For example, a teacher may ask a student to identify the major characters in a story that has just been read. While contextually implicit or inference questions requires answers that can be found in deep structure in text or lesson materials and require inferences beyond surface or literal meanings. For example, a teacher may ask students to read story and then make a judgment about the motives of a major character, even though the author has not made explicit comment about the interaction of this character. And the last, externally implicit or background questions require knowledge of relevant background information not provided in the lesson or text. For example, to answer questions about current events in the GW Marriot, Kuningan requires a wide knowledge of the culture and political context, more than that found in a TV news bulletin or a single issue of a daily newspaper. Students with wide readings of such events are usually able to answer these questions, but those without such reading will have difficulty.

Question given to the students should help them improve their critical and literacy skill. Irwin, (www.PeoplesEducation.com, August, 26, 2009) 'Teachers who teach for meaning and emphasize critical thinking skills in their lessons provide opportunities for students to become independent readers'. One of the strategies to assist students improve their literacy skill is QAR. It provides not only low-level questions but higher-level questions as well. Implementing QAR to plan reading comprehension instruction helps ensure that there will not be an overemphasis of lower-level skills and question that only require students to locate and recall information. It is clear from research that all students need instruction in reading comprehension, especially the kind that focuses on the strategies to answer and generate challenging questions (Taylor, Pearson, Peterson \& Rodriquez, 2003 cited in Raphael \& Au, 2005: 208).

\section{b. THE TYPES OF QUESTION}

There are seven types of questions proposed by Burns, Roe, \& Ross (1990: 203) as follows:

1) Main idea questions: these ask students to identify the central theme of the selection. These may give students some direction toward the nature of the answer. Main idea question help students to be aware of details and the relationship among them. 
2) Detail questions: these ask for bits of information conveyed by the material. Therefore, even though these questions are easy to construct, they should not constitute the bulk of the questions that the teacher asks.

3) Vocabulary questions: these ask for the meaning of words used in the many meanings of a particular word as they can, but purpose questions and test questions should ask for meaning of word as it is used in the selection under the consideration.

4) Inference questions: these require some reading between the lines. The answer to an inference question is implied by the statement in the selection, but it is not directly stated.

5) Sequence questions: these require knowledge of events in their order of occurrence. These check the student's knowledge of the order in which events occurred in the story.

6) Evaluation questions: these questions require the students to make judgments about material. Although these judgments are inference, they depend upon more than the information implied or stated by the story. The students must have enough experience related the situations involved to establish standards for comprehension.

7) Creative response questions: these ask the students to go beyond the material and create new ideas based on the ideas they have read.

\section{c. READING STRATEGY}

The goal of making every student a strategic reader is central to academic reading instruction should be tied to reading strategies, their development, and their use in effective combinations. For any approach to strategy development, students need to be introduced to only a few strategies at a time. Each strategy should be discussed, explained, and modeled. From that point on, the strategies should be reintroduced on a continual basis through teacher reminders, discussions, wall charts, students modeling, and student explanations. Duke and Pearson (2002: 209).

The following strategies are adopted and modified from Sharp (1997: 264-266).

a) Previewing form Main Ideas Previewing can be done by reading the title, if available, every first sentence of each paragraph, and the last sentence of the passage. By previewing, reader can form a general idea of what a reading passage is about; that is, he/she identify the topic. By previewing for main ideas, reader indentifies the point of view of the author-that is, what the writer's thesis is.

b) Using Contexts for Vocabulary

In English a context is the combination of vocabulary and grammar that surrounds a word. Context can be a sentence or a paragraph or a passage. Context helps reader make prediction about meaning. If he/she knows the general meaning of words in sentence.

Making prediction from contexts is very important when a reader is reading a foreign language. In this way, he/she can read and understand the meaning of a passage without stopping to look up every new word in dictionary.

c) Scanning for Details

Scanning can be done by traveling eyes quickly over the passage for the same content words or synonyms of the words. By scanning, a reader can find a place in the reading passage where the answer to a question is found. Finally, he/she may read those specific sentences carefully and choose he answer that corresponds to the meaning of the sentences he/she read.

d) Making inferences

Sometimes, in a reading passage, a reader will find a direct statement or fact. That is called evidence. But other time, he/she has to make an inference. An inference is a logical conclusion 
based on evidence. It can be about the passage itself or about author's view point. The evidence may appear in several sentences of one or some paragraphs of a text. To find evidence, a reader may use skimming strategy by quickly running his/her eyes into whole text.

\section{d. PRE-, DURING-, AND POST- READING FRAMEWORK}

In pre-reading, the teacher, in the first meeting, models each reading strategy to deal with reading comprehension questions. The strategy may be modeled repeatedly until students are familiar with each strategy. He/she then stimulates students to activate backgroud knowledge. Nunan (2003: 74) states that a reader's backgroud knowledge can influence reading brings to a text: life experiences, educational experiences, and knowledge of how texts can be organized. Comprehension can be enhanced if background knowledge can be activated be setting goals, asking questions, asking prediction, teaching text structure and so on. Moreover, Carrell and Floyd (1987) in Ajideh (2003: 5) maintaining that the teacher must provide the students how to build bridges between existing knowledge and new knowledge. Accordingly, the building of bridges between a student's existing knowledge and new knowledge needed for text comprehension.

To stimulate students to activate their background knowledge, teacher may propose question regarding title, if availble, or topic of a text, for instance, if the text entilted "forest", the teacher then may question: "What do you know about the forest?" and /or "What would probably the text discuss about?". The latter, making prediction is aimed at formulating a purpose for reading, to find information. Harmer (2001: 71) asserts that "Prediction is the major factor in reading. When we read texts in our own language, we frequently have a good idea of the content before we actually read". In other word, the students' motivation to read may be aroused by the teacher's asking the students to predict according to the title what the text would discuss. This activity is in accordance with the function of pre-reading phase proposed by William (1987: 2) "the pre-reading phase tries (1) to introduce and arouse interest in the topic; (2) to motivate students by providing reasons for reading or helping them specify their own reason; (3) to provide when necessary some language preparation for the text".

During reading phase, the teacher asks the students to read silently. They read the text with the purpose to find information and curiousity to check whether or not their prediction they made in pre-reading is correct. Afterward, to check students' comprehension, the teacher points the students randomly to ask them questions: main idea question. As the retention, the teacher asks the students to explain each strategy they use to answer each question. In return, the teacher appraises all students' responses through expressions: "well done", "good", "good job", etc. He or she then, provides the correct answers.

In the last or post-reading constitutes a reflection of reading activity. According to William (1987: 2) the aims of post-reading phase are to consolidate or reflect upon what has been red, and to relate the text to the learner's own knowledge, or opinion. In this phase, the teacher asks the students to reflect what they read by proposing questions, e.g. "What would probably happen if the destruction of the forest is not stopped?", "What is your opinion, suggestion to concerve the forest", "What will you do if you get lost in the forest?" "Do you agree at the author's view point?" and so foth. Those questions are intended to facilitate students to think critically and respond creatively using their schemata to evaluate, give opinion, and 
purpose solution as reflection of what they read. If the students then seem confuse to answer those questions and spend too much time searching, on and on, for the answer inside the text, the teacher must tell the students that the questions require them to use their mind. Thus they must think and activate their schemata for the answer. Other activities in this phase, the teacher and students may have are indentifying vocabulary using contect, detecting reference, and recognizing cohesive devices and other language features.

\section{CONCLUSION}

This article provides a paragdigm to assist teacher to well facilitate his/her students in order to be good and proficient reading. There are, at least, three concerns which the teacher should undretake in his/her reading classroom activity; 1) the teacher should involve both lower-, and higher-level questions; 2) the teacher should equip students with explicit reading strategy; 3) the teacher should be aware of the activities in reading phases: pre-, during-, and post-reading.

\section{REFERENCES}

Abrami, P. C., Chambers, B., Poulsen, C., Simone, C. D., D'Apollonia, S., \& Howden, J. (1995). Classroom connections: Understanding and using cooperative learning. Toronto: Harcourt Brace \& Company Canada, Ltd.

Aebersold, Jo Ann \& Field, Mary Lee. 1997. from Reader to Reading Teacher: Issues and Strategies for Second Language Classrooms. Cambridge: Cambridge University Press.

Ajideh, Parviz. 2003. Schema TheoryBased Pre-Reading Tasks: A Neglected Essential in the ESL Reading-Class. The Reading Matrix. Vol.3. No.1, April 2003. Available http://www.readingmatrix.com/art icles/ ajideh/article.pdf

Brown, H. Dauglas. 2000. Principles of Language Learning and Teaching. New York: Addison Wesley Longman, Inc. United States of America: Longman. 2001. Teaching by

Principles: An Interactive Approach to Language Pedagogy. New York: Addison Wesley Longman, Inc. United States of America: Longman.

Burn \& Roe \& Ross. 1984. Teaching Reading in Today's Elementary School. USA: Houghton Mifflin Company

Deboer, John J. \& Dallman, Martha. 1966. The Teaching of Reading. USA: Holt, Reinehart and Winston, Inc.

Duke, Nell K. \& Pearson, P. David. 2001. Effective Practices for Developing Reading Comprehension. Professional article Available at: www.nationalgeographic.dom

Elliott, Stephen N. 1999. Educational Psychology: Effective Teaching, Effective Learning, Second Edition International Edition. Singapore: McGraw-Hill Book Co.

Grabe, William \& Fredricka L. Stoller. 2001. Reading for Academic Purposes: Guidelines for the ESL/EFL Teacher. United States of America: Heinle \& Heinle, a division of Thomson Learning, Inc.

Harmer, Jeremy. 2001. The Practice of English Language Teaching: Third Edition Completely Revised and Updated. Essex: Longman.

Harris, A. J. \& Sipay, E.T. (1980). How to Increase Reading Ability. New York. USA: Longman Inc.

Harris, Robert. 2010. Some Ideas for Motivating Students. Available at: http://www. virtualsalt.com 
Heilman, Arthur W. 1964. Principle and Practice of Teaching Reading. Columbus, Ohio: Charles E. Merill Books, Inc.

Helping Students Become Motivated

Learners. Available at:

http://www.ndt-ed.org/

TeachingResources/ClassroomTip s/Motivating_Students.htm

Irwin, Joan. Reseach Base for Critical Reading: Differential Instruction Across Genres. Available at: http://www.nationalgeographic.co m.au/ngextreme explorer/pdf/ effective practices.pdf.

Miles, Mathew \& Huberman, A. Michael. 1984. A Qualitative Data Analysis. Sage Publication, Inc.

Mills, G.E. 2000. Action Research: A Guide for the Teacher Researcher. New Jersey: Prentice Hall.

Nunan, David. 1992. Cooperative Language Learning and Teaching. Cambridge: Cambridge University Press.

2003. Practical English Language Teaching. New York: Mc. GrawHill.

Nuttal, Christine. 1996. Teaching Reading Skill in a Foreign Language. Heinemann: Heinemann English Language Teaching.

Reading for A Purpose. Available at: www.schools.nsw.edu.au/media/d ownloads $/ . . . / \mathrm{k}$.../srft_24_25.pdf

Reading for the $21^{\text {st }}$ Century: Adolescent Literacy Teaching and Learning Strategies. Alliance for Excellent Education Journal: Issue Brief, January 2004. Available at: http://www.all4ed.org/files/Readin g_21stCentury.pdf

Ricards, Jack C. 1996. Reflective Teaching in Second Language Classrooms. New York: Cambridge University Press.
Silberstein, Sandra. 1994. Techniques and Resources in Teaching Reading. Oxford: Oxford University Press.

Snow, Cahterine. 2002. Reading for Understanding: Toward an $R \& D$ Program in Reading Comprehension. Santa Monica, CA: RAND.

Stahl, Katherine A. Daugherty. 2004. Proof, Practice, and Promise: Comprehension Strategy Instruction in The Primary Grades. The Reading Teacher. Vol. 57, No. 7 April 2004.

Urgurhart, Sandy \& Weir, Cyril. 1998. Reading in a Second Language Process, Product and Practice. London: Longman.

William, Eddie. 1987. Classroom Reading Through Activating Content-based Schemata. Available at: flrc.hawaii.edu/rfl/PastIssues/rfl4 lwilliams.pdf.

1996. Reading in the Language Classroom. London: Modern English Publication 